\title{
Supraglottic Airway Devices: A Knock of Future
}

\author{
Anisha S* and Lalit G \\ Department of Anesthesiology \& Critical Care, Maulana Azad Medical College, \\ University of Delhi, India
}

${ }^{*}$ Corresponding author: Anisha Singh, Department of Anesthesiology \& Critical Care, Maulana Azad medical college, New Delhi University of Delhi, India, Tel: 09810341603;

Email: anisha_sngh@yahoo.co.in

\section{Review Article \\ Volume 3 Issue 1}

Received Date: March 14, 2018

Published Date: April 20, 2018

\section{Abstract}

Supraglottic airway devices (SGAs) have become an important part of anesthesia management. They comprise of varied group of medical devices inserted through mouth for achieving oxygenation, ventilation as well as conduit for intubation in both elective and emergency situations. These have an advantage of being more definitive airway compared to facemask and less invasive than end tracheal intubation. The newer generation devices with improved safety features have almost replaced the golden era of endo tracheal tube in certain cases. Several SGAs have many distinctive features that are time tested in various difficult scenarios, which has led to an array of newer armamentarium in the kit of anesthetist for its selection in distress. This demands the knowledge of their specificities and since new devices are always being introduced, continuous learning is paramount. This review highlights the new era of supraglottic devices along with describing certain routinely used SGAs in clinical practice.

Keywords: Supraglottic airway devices; Laryngeal mask; Airway management; ventilation; Respiratory failure

Abbreviations: SGAs: Supraglottic Airway Devices; ETT: End Tracheal Tube; OLP: Orpharyngeal Leak Pressure; SLIPA: Streamlined Liner of the Pharyngeal Airway; RCTs: Randomized Controlled Trials.

\section{Introduction}

The term Supraglottic airway or extraglottic [1,2] airway or supralaryngeal [3] airways are widely used by various authors in literature. All of these refer to the same diverse family of medical devices mentioned under the name of supraglottic airway devices (SGAs) in this context. SGAs of different and improved designs are available and widely used in current clinical practice as a primary airway management device, rescue airway device and a conduit for end tracheal intubation [4]. These have advantage of being easy to insert, less invasive, stable hemodynamic, no requirement of deep plane of anesthesia for successful placement and insertion.

\section{Historical Perspective}

In 20th Century, Dr. Archie Brain suggested that use of supraglottic devices would be less traumatic than end tracheal tube (ETT) and more reliable than the face mask. In 1981, he glued a diagonally cut, $10 \mathrm{~mm}$ portex ETT to the Goldman dental rubber mask's attachment flange, which he extended across the mask aperture into midline 


\section{Anaesthesia \& Critical Care Medicine Journal}

to form a base [5,6]. It was Dr. Brain's intent to mimic the placement of food into the hypo pharynx and thereby establish the placement of a device, which could then serve as an airway. All varieties of the laryngeal mask airways follow the same insertion technique. The insertion technique is similar to the process of deglutination which includes lubrication with a non silicone, non local anesthetic-containing lubricant (saliva) and is fully deflated to form a thin, flat wedge shape (masticated food bolus) (Figure 1). SEALING PRESSUREThe airway sealing pressure or the orpharyngeal leak pressure (OLP) is the pressure at which gas leak occurs around the device. It is important as it indicates the degree of airway protection and feasibility of positive pressure ventilation. It quantifies the efficacy of seal with the airways and is also an index of successful placement. After the placement of airway device, OLP is determined by closing the expiratory valve of the closed circle system at a fixed gas flow of $3 \mathrm{~L} / \mathrm{min}$. There are various methods of assessing this pressure.

a) Audible noise over the mouth of the patient

b) Manometer stability- observation of aneroid manometer dial and noting the airway pressure at which the dial attains stability( i.e. the airway pressure at which the leak was in equilibrium with the fresh gas flow)

c) Auscultation involves detection of an audible noise using a stethoscope placed just lateral to the thyroid cartilage.

d) Since the introduction of laryngeal mask airway, many more supraglottic devices are being developed and are being continuously improved with new features.

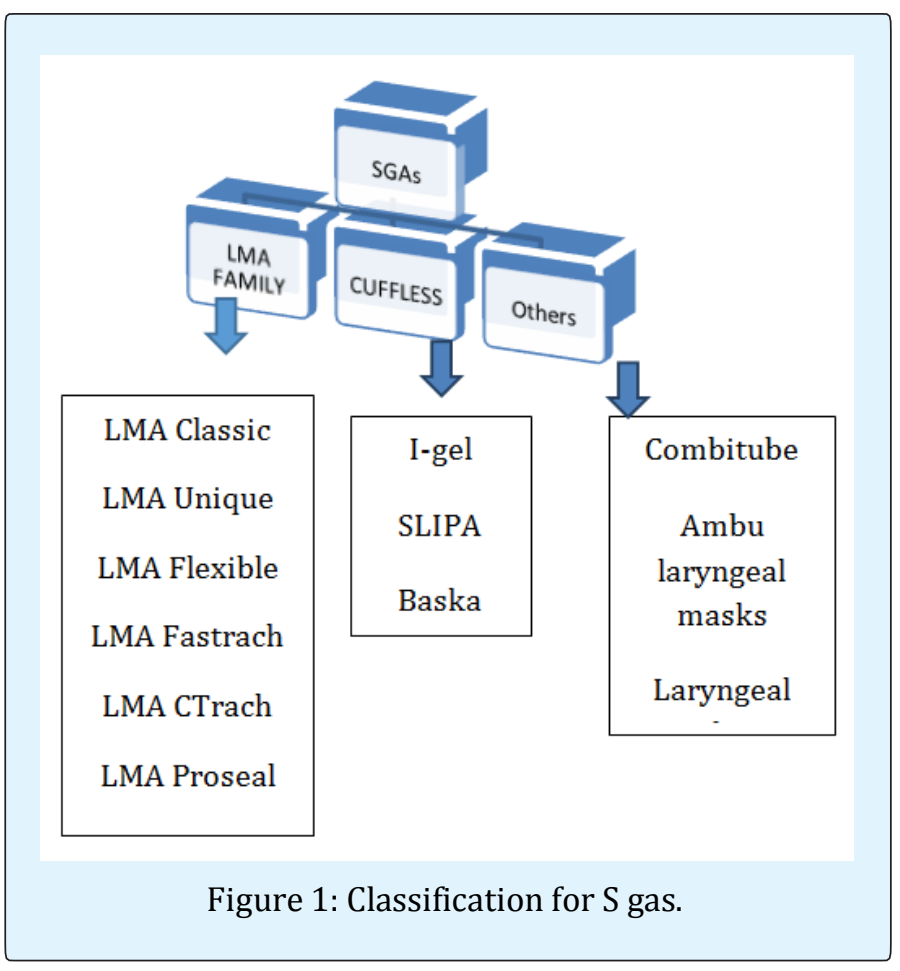

There is need to follow a simplified classification of supraglottic airway devices as earlier, in literature a lot of methods have been mentioned by various authors [7-9] to classify these devices. The most sensible and easy to remember have been mentioned here in details.

\section{Based on Sealing Mechanisms}

a) Per laryngeal sealers: The LMA family, I-gel and Air-Q Intubating Laryngeal Airway (Air-Q ILA) b) Pharyngeal sealers: Combitube, the Streamlined Liner of the Pharynx Airway (SLIPA), the Laryngeal Tube (LT)

c) Both: The Cobra Perilaryngeal Airway (CobraPLA) [10]

\section{Based On Evolution}

1. First-generation devices: Simple airway tubes

- The laryngeal mask airway [classic LMA (CLMA)], flexible LMA (FLMA), unique LMA (ULMA) and The Cobra Perilaryngeal Airway (CobraPLA), Combi-tube. 


\section{Anaesthesia \& Critical Care Medicine Journal}

2. Second-generation devices: With addition of Drainage tube

- Pro Seal LMA (PLMA), I-gel, Laryngeal tube, LMA Supreme, Streamlined Liner of the Pharyngeal Airway (SLIPA) [11] (Table 1).
3. Third-generation devices: with self-energizing sealing mechanism

- The Baska airway

\begin{tabular}{|c|c|c|c|c|c|c|c|}
\hline $\begin{array}{c}\text { SGA } \\
\text { name }\end{array}$ & $\begin{array}{c}\text { SGA } \\
\text { Generation }\end{array}$ & Sealing mechanism & \begin{tabular}{|c|} 
Year of \\
Introduction
\end{tabular} & Available size & $\begin{array}{c}\text { OLP } \\
(\mathrm{cmH2o}) \\
\end{array}$ & Usage & \begin{tabular}{|l}
$\begin{array}{l}\text { Conduit for } \\
\text { intubation }\end{array}$ \\
\end{tabular} \\
\hline PLMA & 2nd & $\begin{array}{c}\text { Inflatable } \\
\text { uff }\end{array}$ & 2000 & Pediatric-1,1.5,2,2.5 & 30 & Reusable (40 & No \\
\hline I-gel & 2nd & Cuffless,preformed & 2007 & $\begin{array}{c}\text { Pediaatric-1,1.5,2,2.5 } \\
\text { Adult-3,4,5 }\end{array}$ & 27 & Single use & YES \\
\hline SLMA & 2nd & $\begin{array}{c}\text { Inflatable } \\
\text { cuff,perilaryngeal }\end{array}$ & 2007 & $\begin{array}{c}\text { Pediatric-1,1.5,2,2.5 } \\
\text { Adult-3,4,5 }\end{array}$ & 27 & Single use & No \\
\hline $\begin{array}{c}\text { LMA } \\
\text { Fastrach }\end{array}$ & $1 \mathrm{st}$ & $\begin{array}{c}\text { Inflatable } \\
\text { cuff,perilaryngeal }\end{array}$ & 1997 & Adult-3,4,5 & 20 & $\begin{array}{l}\text { Single use \& } \\
\text { reusable ( } 40 \\
\text { times ) }\end{array}$ & Yes \\
\hline Cobra & $1 \mathrm{st}$ & $\begin{array}{l}\text { Cuffed pharyngeal } \\
\text { sealer }\end{array}$ & 1997 & $\begin{array}{c}\text { Pediatric-0.5,1,1.5,2 } \\
\text { Adult- } 3,4,5,6\end{array}$ & $24-27$ & Single use & yes \\
\hline SLIPA & $1 \mathrm{st}$ & Cuffless,preformed & 2004 & $\begin{array}{c}\text { Adult- } \\
47,49,51,53,55,57\end{array}$ & 30 & Single use & No \\
\hline $\begin{array}{l}\text { Baska } \\
\text { mask }\end{array}$ & $3 \mathrm{rd}$ & Cuffless,self-sealing & 2011 & $\begin{array}{c}\text { Pediatric-1,1.2,2,2.5 } \\
\text { Adult-3,4,5,6 }\end{array}$ & $>30$ & $\begin{array}{l}\text { Single use \& } \\
\text { reusable (60 } \\
\text { times) }\end{array}$ & No \\
\hline
\end{tabular}

Table 1: Routinely Used Sgas.

\section{Intubating LMA (Fastrach)}

LMA fastrach had been devised for blind intubation with end tracheal intubation in adult patients $[11,12]$. It has a preformed anatomical curve with a steel handle and a movable epiglottic elevating bar. It can be used both for ventilation and intubation with $96 \%$ success rate [13-15]. Designed for the anticipated or unanticipated difficult airway situation and for cardiopulmonary resuscitation (Figure 2).

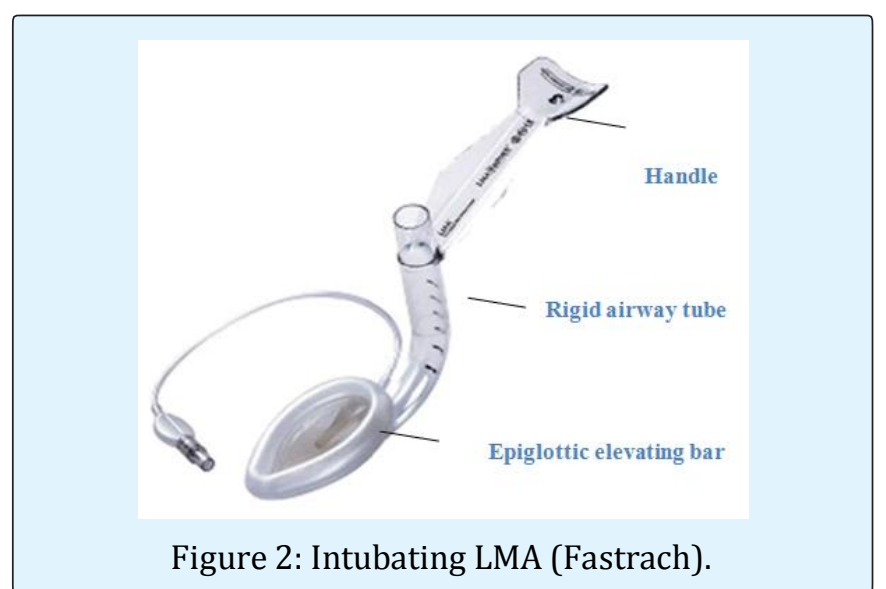

\section{LMA ProSeal (PLMA)}

The LMA ProSeal (PLMA), is a reusable second generation device which was introduced into clinical practice in 2000. It has an inflatable mask made of silicone with an additional dorsal cuff to provide better seal. It has a double tube arrangement with a flexible wire reinforced airway tube and a drain tube. Attached to the mask is an inflation line terminating in a pilot balloon and valve for mask inflation and deflation. A red plug is also fitted to the valve which is utilized in steam sterilization. Deeper bowl is present to increase the sealing pressure. An accessory vent facilitates ventilation and collects secretions [16]. A removable introducer tool and a dedicated deflation device is available to aid insertion. According to the manufacturer's recommendations PLMA may be used to maximum 40 times before being discarded. 7 sizes are available. Sizes 1-21/2have no dorsal cuff. Insertion techniques have been recommended which include use of an introducer tool, the index finger technique, and insertion over a gum elastic bougie or gastric tube or suction catheter placed into esophagus via the drainage tube (Figure 3). 


\section{Anaesthesia \& Critical Care Medicine Journal}

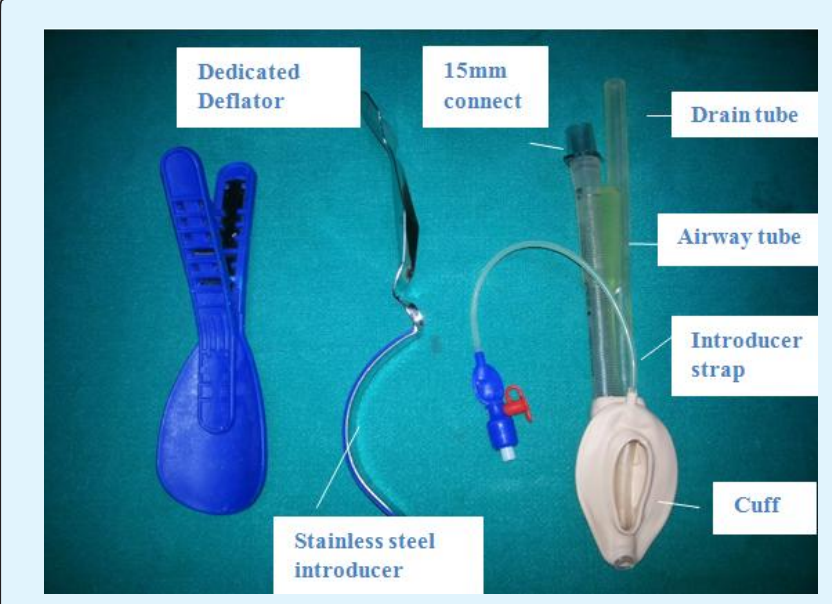

Figure 3: LMA ProSeal, Deflator, Introducer.

\section{I-GEL}

The I-gel [17] (Intersurgical, Berkshire, Wokingham, UK) is a single use second generation SGAs designed by $\mathrm{Dr}$ Md. Aslam Nasir in January 2007. It is made of amedical grade gel like thermoplastic elastomer (styrene ethylene butadiene styrene) and it mirrors the anatomy of the airway and the airway seal improves as the device warms to the body temperature. The soft, non inflatable cuff fits snugly onto the per laryngeal structures. The firmness of tube section and its natural or pharyngeal curvature allows the device to be inserted by grasping the proximal end of it against the hard palate into the pharynx without inserting the fingers into the mouth of the patients. It is available in 7 different sizes $(1,1.5,2,2.5,3,4,5)$ and is supplied in an innovative, colour coded polypropylene protective cradle. An additional benefit of this device is that it may be used as a rescue airway and fiberoptic conduit when intubation is difficult or unsuccessful $[18,19]$ (Figure 4).

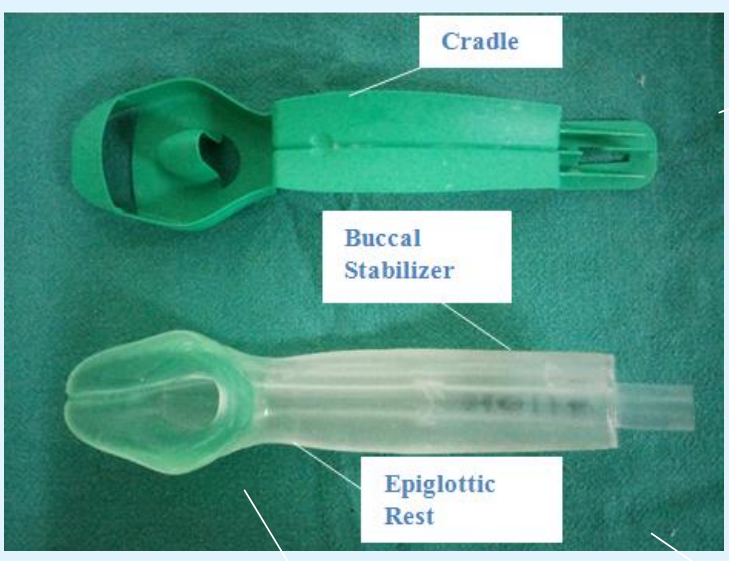

Figure 4: I-gel with cradle.

\section{LMA Supreme (SLMA)}

LMA Supreme [20] is a single use, latex free, second generation SGAs and is made of medical grade polyvinyl chloride. It was introduced in 2007 and has a larger precurved cuff for an improved fit and an effective high seal which facilitates ventilation and a moulded distal cuff to resist folding. It has a preformed fixed curved tube to facilitate insertion and a fixation tab which excludes the use of introducer or putting fingers inside the patient's mouth, therefore prevents disease transmission. Epiglottic fins have been added to prevent epiglottic down folding. The distance of fixation tab to the upper lip should be $1.5-2 \mathrm{~cm}$. if the tab is flush against the upper lip, a larger size SLMA should be used. It is designed to secure the device and to maintain proper cuff depth. SLMA is available in 7 sizes. Ease of insertion, presence of a gastric port, and the option for using higher ventilatory pressures make the LMA Supreme more versatile and applicable for use in higher risk patients (Figure 5).

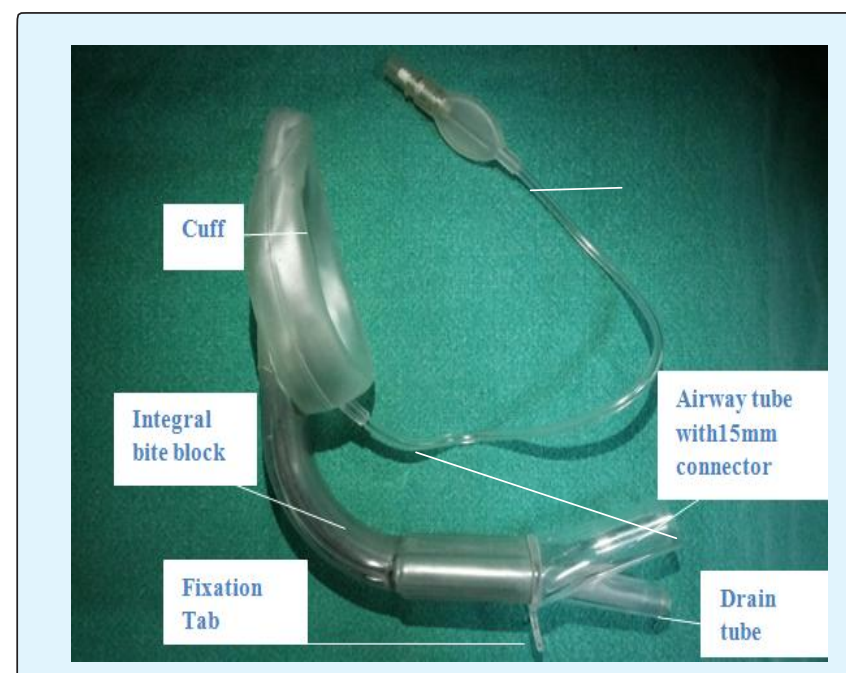

Figure 5: LMA Supreme.

\section{Cobra Per Laryngeal Airway}

It is a novice per laryngeal airway having a breathing tube with a wide distal end and a cuff attached just proximal to the wide part. The cuff, when inflated, serves to seal off the distal end from the upper airway. The wide end holds both soft tissues and the epiglottis away from the distal portion. Large cuff is of significant importance as this allows providing higher sealing pressures than the classic LMA [21] (Figure 6). 


\section{Anaesthesia \& Critical Care Medicine Journal}

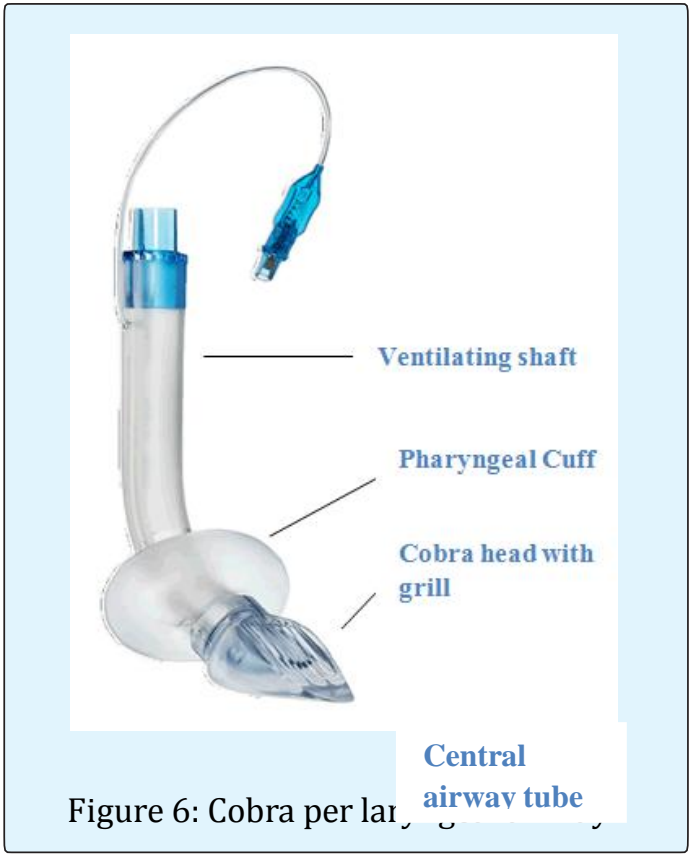

\section{Streamlined Liner of the Pharynx Airway (SLIPA)}

It is acuffless device, shaped like a hollow boot with "toe," "bridge," and "heel" prominences, which seals the patient's pharynx without the use of an inflatable cuff. It has a hollow chamber that can store up to $50 \mathrm{~mL}$ of drained gastric fluid, hence prevents aspiration risk [22] It provides sealing pressure comparable to PLMAi. e $30 \mathrm{~cm}$ $\mathrm{H}_{2} \mathrm{O}$ [23] (Figure 7).

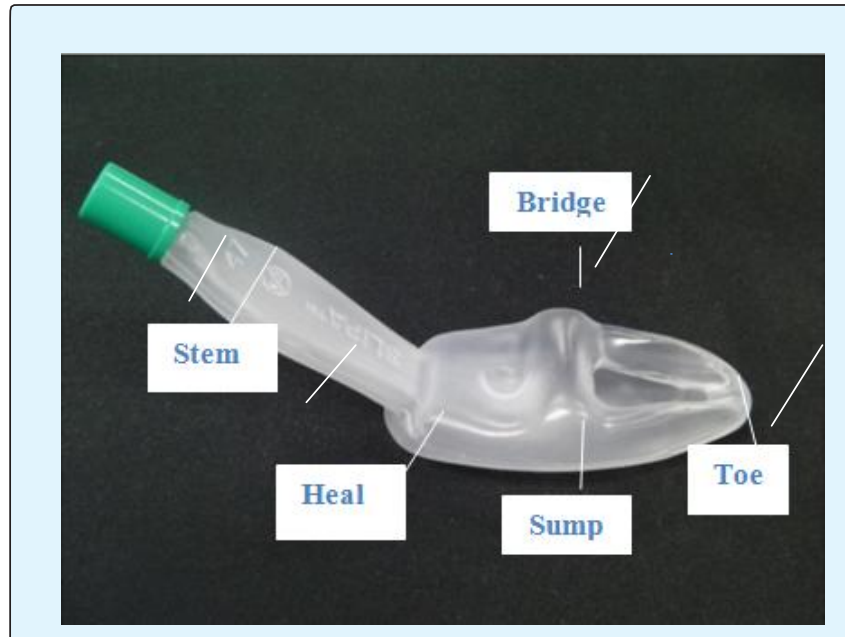

Figure 7: SLIPA.

\section{Bask Mask}

The Baska mask belongs to the third generation. It brings together features of:

a) The LMA-Pro Seal (high seal pressure, gastric port and bite block)

b) The LMA-Supreme (oval shaped, anatomically curved airway tube with a gastric port

c) The I-gel (gel like membranous diaphragm instead of an inflatable balloon)

d) The SLIPA (cuff less sump). It contains 2 gastric drain tubes with $90^{\circ}$ suction elbow port for keeping sump area clear. The Baska Mask is unique in terms of a bite block incorporated throughout the entire length of the airway tube. The oval-shaped airway tube matches the shape of the mouth and reduces rotation within the pharynx (Figure 8).

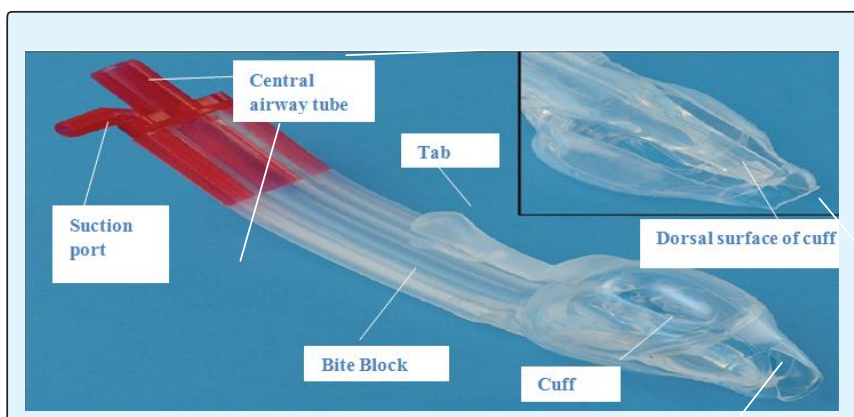

Figure 8: Baska airway.

\section{Special Clinical Applications of Sgas: Opening of New Horizon}

Laparoscopic surgery: The indications for use of the supraglottic airway devices are expanding. Their routine use in laparoscopic surgeries has almost replaced the endotracheal tubes. SGAs containing an additional drain tube have proved to provide adequate sealing pressure required to maintain airway safety and providing adequate ventilation [24]. In addition, associated pharyngolaryngeal morbidity (sore throat, dysphagia, dysphonia) are less with SGAs as compared to endotracheal tube $[25,26]$.

Obese Patients: In today $s$ era, the number of obese patients undergoing surgeries is increasing. Some randomized controlled trials (RCTs) have compared SGAs to endotracheal tubes with respect to airway access which has been summarized in a meta-analysis following Cochrane criteria [27]. Accordingly, SGAs after successful placement can provide better postoperative pulmonary 


\section{Anaesthesia \& Critical Care Medicine Journal}

performance if used in very well selected patients. These maybe used as conduits for tracheal intubation in obese patients with failed laryngoscopy and expected/unexpected difficult airways [28].

Pregnancy: SGAs can be lifesaving in cesarean deliveries where scenarios of cannot ventilate and cannot incubate is faced. The second generation SGAs can be used to secure airway to save time consumed when in emergent situations. Although cuffed endotracheal tubes securing the airway remains the gold standard practice in all general anesthesia obstetric cases, but SGAs use in caesarean sections has been described in the literature [29].

Pediatric Age Group: SGAs are now routinely used in children because they typically are more user-friendly and avoid many of the problems associated with end tracheal intubation [30]. The LMA Classic and the LMA Proseal are now established in terms of safety and efficacy for routine as well as in emergency cases in pediatric patients. Recently developed non-inflatable devices, the SLIPA and I-gel, await more clinical trials to establish their suitability in children. Still, the evolving SGAs have dawned a new era announcing new horizons in pediatric airway management.

\section{Conclusion}

SGAs are being evolved with newer designs and features to achieve utmost safety for use in clinical practice. But the search for the ideal SGAs is still going on which would almost replace the endotracheal tubes and all co-morbidities associated with intubation. Most of the international airway management guideline lists SGAs between mandatory devices in emergency airway cart, for airway rescue management in difficult situations. The fast learning curve for use of SGAs can be utilized in resuscitation even by novice users, which can be a boon in saving lives.

\section{References}

1. Michálek P, Miller DM (2014) Airway management evolution - in a search for an ideal extraglottic airway device. Prague Med Rep 115(3-4): 87-103.

2. Ramaiah R, Das D, Bhananker SM, Joffe AM (2014) Extraglottic airway devices: A review. Int J Crit Illn Inj Sci 4(1): 77-87.

3. Polat R, Aydin GB, Ergil J, Sayin M, Kokulu T, et al. (2014) Comparison of the i-gel TM and the Laryngeal
Mask Airway Classic TM in terms of clinical performance. Brazilian J Anesthesiol 65(5): 343-348.

4. Hagberg C, Artime C (2015) Airway management in the adult. In RD Miller et al., Miller's Anesthesia, $8^{\text {th }}$ (Edn.), pp: 1661.

5. Brain AJ (1991) The development of the Laryngeal Mask-a brief history of the invention, early clinical studies and experimental work from which the Laryngeal Mask evolved. Eur J Anesthesiol 4: 5-17.

6. Pennant JH, White PF (1993) The laryngeal mask airway. Its uses in anesthesiology. Anesthesiology 79(1): 144-163.

7. Brain AI (1983) The laryngeal mask-a new concept in airway management. Br J Anaesth 55(8): 801-805.

8. Cook T, Howes B (2011) Supraglottic airway devices: Recent advances. Contin Educ Anaesthesia, Crit Care Pain 11(2): 56-61.

9. Hernandez MR, Klock PA Jr, Ovassapian A (2012) Evolution of the extraglottic airway: a review of its history, applications, and practical tips for success. Anesth Analg 114(2): 349-368.

10. Miller DM (2004) A proposed classification and scoring system for supraglottic sealing airways: a brief review. Anesth Analg 99(5): 1553-1559.

11. Cook T, Howes B (2011) Supraglottic airway devices: Recent advances. Contin Educ Anaesthesia, Crit Care Pain 11(2): 56-61.

12. Gerstein NS, Braude DA, Hung O, Sanders JC, Murphy MF (2010) The Fastrach Intubating Laryngeal Mask Airway: an overview and update. Can J Anaesth 57(6): 588-601.

13. Lu PP, Yang CH, Ho AC, Shyr MH (2000) The intubating LMA: a comparison of insertion techniques with conventional tracheal tubes. Can J Anaesth 47(9): 849-853.

14. Ferson DZ, Rosenblatt WH, Johansen MJ, Osborn I, Ovassapian A (2001) Use of the intubating LMAFastrach in 254 patients with difficult-to-manage airways. Anesthesiology 95(5): 1175-1181.

15. Kapoor S, Jethava DD, Gupta P, Jethava D, Kumar A (2014) Comparison of supraglottic devices i-gel(囚) 


\section{Anaesthesia \& Critical Care Medicine Journal}

and LMA Fastrach $(\circledR)$ as conduit for endotracheal intubation. Indian J Anaesth 58(4): 397-402.

16. Brain AIJ, Verghese C, Strube PJ (2000) The LMA 'ProSeal-a laryngeal mask with an esophageal vent. $\mathrm{Br}$ J Anaesth 84(5): 650-654.

17. I-gel User Guide, Wokingham, UK: Intersurgical Ltd, 2012.

18. Jackson KM, Cook TM (2007) Evaluation of four airway training manikins as patient simulators for the insertion of eight types of supraglottic airway devices. Anaesthesia 62(4): 388-393.

19. Wharton NM, Gibbison B, Gabbott DA, Haslam GM, Muchatuta N, et al. (2008) I-gel insertion by novices in manikins and patients. Anaesthesia 63(9): 991995.

20. Verghese C, Ramaswamy B (2008) LMA- Supreme TM-a new single-use LMATM with gastric access: a report on its clinical efficacy. Br J Anaesth 101(3): 405-410.

21. Ocker H, Wenzel V, Schmucker P, Steinfath M, Dörges $\mathrm{V}$, et al. (2002) A comparison of the laryngeal tube with the laryngeal mask airway during routine surgical procedures. Anesth Analg 95(4): 1094-1097.

22. Miller DM, Light D (2003) Laboratory and clinical comparisons of the Streamlined Liner of the Pharynx Airway (SLIPA) with the laryngeal mask airway. Anaesthesia 58(2): 136-142.

23. Hoi YM, Cha SM, Kang H, Baek CW, Jung YH, et al. (2010) the clinical effectiveness of the streamlined liner of pharyngeal airway (SLIPATM) compared with the laryngeal mask airway ProSeal TM during general anesthesia. Korean J Anesthesiol 58(5): 450-457.

24. Cook T, Howes B (2011) Supraglottic airway devices: recent advances. Continuing Educ Anaesth Crit Care Pain 11(2): 56-61.

25. Carron M, Veronese S, Gomiero W, Foletto M, Nitti D, et al. (2012) Hemodynamic and hormonal stress responses to endotracheal tube and ProSeal Laryngeal Mask Airway TM for laparoscopic gastric banding. J Am Soc Anesthesiol 117(2): 309-320.

26. Ulrich-Pur H, Hrska F, Krafft P, Friehs H, Wulkersdorfer B, et al. (2006) Comparison of mucosal pressures induced by cuffs of different airway devices. J Am Soc Anesthesiol 104(5): 933-938.

27. Nicholson A, Cook TM, Smith AF, Lewis SR, Reed SS (2013) Supraglottic airway devices versus tracheal intubation for airway management during general anaesthesia in obese patients. Cochrane Database Syst Rev 9(9): CD010105.

28. Henderson JJ, Popat MT, Lotto IP, Pearce AC (2004) Difficult Airway Society guidelines for management of the unanticipated difficult intubation. Anaesthesia 59(7): 675694.

29. Verghese C, Brimacombe JR (1996) Survey of laryngeal mask airway usage in 11,910 patients: safety and efficacy for conventional and nonconventional usage. Anesth Analg 82(1): 129-133.

30. Ramesh S, Jayanthi R (2011) Supraglottic airway devices in children. Indian Journal of Anaesthesia 55(5): 476482. 